\title{
Self-healing coatings in anti-corrosion applications
}

\author{
Alicja Stankiewicz • Irena Szczygieł • \\ Bogdan Szczygieł
}

Received: 4 April 2013/Accepted: 20 July 2013/Published online: 1 August 2013

(C) The Author(s) 2013. This article is published with open access at Springerlink.com

\begin{abstract}
Nonmetallic (based on polymers or oxides) and metallic protective coatings are used to protect metal products against the harmful action of the corrosion environment. In recent years, self-healing coatings have been the subject of increasing interest. The ability of such coatings to self-repair local damage caused by external factors is a major factor contributing to their attractiveness. Polymer layers, silica-organic layers, conversion layers, metallic layers and ceramic layers, to mention but a few, are used as self-healing coatings. This paper presents the main kinds of self-healing coatings and explains their selfhealing mechanisms.
\end{abstract}

\section{Introduction}

The surfaces of metal products are protected against the detrimental effect of the corrosion environment by organic or inorganic metallic coatings. Depending on the type of coating, the operating environment and the required protection time, such coatings are produced using different methods, i.e. traditional methods (e.g. immersion and electrochemical deposition) or methods requiring the use of modern equipment (e.g. PVD, CVD and laser plating). Most often, constructions made of steel and magnesium and aluminium alloys are protected in this way.

\footnotetext{
A. Stankiewicz $(\square) \cdot$ I. Szczygieł

Department of Inorganic Chemistry, Wrocław University of Economics, ul. Komandorska 118/120, 53345 Wrocław, Poland e-mail: alicja.stankiewicz@ue.wroc.pl

B. Szczygieł

Faculty of Chemistry, Wrocław University of Technology, Wybrzeże Wyspiańskiego 27, 50370 Wrocław, Poland
}

It is required of new-generation protective coatings to intelligently respond to mechanical or chemical damage caused by the external environment and to reproduce their original properties, including their adhesion to the substrate and integrity. The self-healing ability is a particularly vital property for coatings designed to protect the material of a construction against corrosion. According to the data provided by Engineering Village, quoted by Aïssa et al. [1], in the years 2000-2010, the number of publications on smart coatings increased tenfold. Until recently, the main components of self-healing anti-corrosion coatings have been chromium(VI) compounds. Their self-healing mechanism consists of forming a protective oxide film in the damaged area. The introduction of restrictions on the use of $\mathrm{Cr}(\mathrm{VI})$ containing compounds spurred research aimed at developing substitutes for such coatings. Today, self-healing anti-corrosion coatings are produced using macromolecular compounds, ceramics, metals and composites. The coatings often contain cerium, sodium tetraoxomolybdate, colloidal silica and fluoro-organic compounds. The properties of such coatings are activated by appropriate stimuli: temperature changes, radiation, $\mathrm{pH}$ changes, pressure changes and mechanical action.

This paper presents the existing knowledge on selfhealing coatings used in anti-corrosion protection. In the successive chapters, the coatings are classified and described according to the kind of material and the method of coating. Also, methods aiding the assessment of the properties of self-healing coatings are presented.

\section{Polymeric coatings}

Owing to their easy modifiability, whereby the desired useful properties can be obtained, polymers and the 
composites which contain them belong to the materials most often used to produce self-repair coatings [2-16]. The ease of modification stems from the various properties of macromolecular compounds, such as oxidizing properties, swelling and cross-linking ability, and from the fact that no high temperatures are required to form them. The smart functionality can be based on functional additives (corrosion inhibitors) or the polymeric structure [17]. In the literature, one can find descriptions of coatings composed of

- a superabsorbent polymer ((SAP), known under the trade name 'AQALIC CS-7S', Nippon Shokubai Co. Ltd.), and a vinyl ester polymer (VEP) [9];

- polystyrene sulphonate ion-exchange resin [12];

- polyaniline (PANI) with molybdate ions $\left(\mathrm{PANI}-\mathrm{MoO}_{4}{ }^{2-}\right.$ ) [2];

- polyaniline and silica sol-gel (PANI/sol-gel) [4];

- dodecylbenzenesulfonicacid-doped polyaniline nanoparticles (n-PANI(DBSA)) and neat epoxy ester [3];

- copolymer HFBMA-co-ITEGMA (HFBMA-2,2,3,4, 4,4-hexafluorobutyl methacrylate; ITEGMA-isocyanate groups containing methacrylate monomer) [6];

- polypyrrole doped with heteropolyanions of $\mathrm{PMo}_{12}$ $\mathrm{O}_{40}{ }^{3-}$ and $\mathrm{HPO}_{4}{ }^{2-}$ [5];

- metallo-supramolecular gels containing 2,6-bis(1,2,3trizol-4-yl)pyridine (BTP) [15];

- $\operatorname{poly(vinylidene~fluoride)~(PVDF)~[7];~}$

- Ruthenium Grubbs' Catalyst (RGC) nanoparticles in 5-ethylidene-2-norbornene (5E2N) matrix [8];

- epoxy vinyl ester [18];

- epoxy (Epon $\left.{ }^{\circledR} 828\right)$ with $12 \mathrm{wt} \%$ diethylenetriamine [18];

- epoxy resin (6071, Ciba Geigy) with poly(o-phenylenediamine) nanotubes (PoPD nanotubes) [19];

- vinyl ester polymer with rutile [10];

- epoxy materials based on maleimide chemistry [16];

- chitosan [14];

- polyelectrolytes, for example, poly(allylamine hydrochloride) (PAH), poly(ethylene imine) (PEI) with 2-(benzothazol-2-ylsulfanyl)succinic acid (BYS) [11];

- $\quad$ porous polymer based on cellulose (CAF) [13].

In the case of the particular materials, self-healing is governed by different mechanisms. Conductive polymers, i.e. (PPy) or polyalinine (PANI), have oxidizing properties causing steel passivation. In the case of polypyrrole having ion-exchange properties, when it is modified with $\mathrm{PMo}_{12} \mathrm{O}_{40}{ }^{3-}$ and $\mathrm{HPO}_{4}{ }^{2-}$ ions, self-healing is additionally achieved owing to the reaction of tetraoxomolybdate ions $\left(\mathrm{MoO}_{4}{ }^{2-}\right)$ with iron. The forming iron molybdate significantly limits substrate digestion. $\mathrm{MoO}_{4}{ }^{2-}$ ions form via the hydrolysis reaction [5]:
$\mathrm{PMo}_{12} \mathrm{O}_{40}^{3-}+12 \mathrm{H}_{2} \mathrm{O} \rightarrow 12 \mathrm{MoO}_{4}^{2-}+\mathrm{HPO}_{4}^{2-}+23 \mathrm{H}^{+}$

Polyaniline with molybdate ions prevents an iron dissolution reaction. It has been reported that conductive polymers, such as polyaniline, in their conductive states can be responsible for displacing the electro-active interface from its usual location. PANI- $\mathrm{MoO}_{4}{ }^{2-}$ is an oxidizer which offers anodic galvanic protection to the substrate [2]. Molybdate anions perform a similar function as in the case of PPy coatings enriched with $\mathrm{PMo}_{12} \mathrm{O}_{40}{ }^{3-}$ and $\mathrm{HPO}_{4}{ }^{2-}$ ions. The self-healing mechanism of epoxy esters resin with $n$-PANI(DBSA) consists of releasing $\mathrm{DBSA}^{-}$anions which by reacting with iron cations cause the formation of an additional layer at the end of the coating pores [3]. The PANI/sol-gel coating provides corrosion protection for aluminium alloy through a selfrepair mechanism thanks to the ability of polyaniline to undergo a redox reaction. Polyaniline undergoes a phase transformation from the emeraldine base form to the leucoemeraldine form [4].

AQALIC CS-7S is a polymer which can absorb water and swell. Thanks to these properties, it is used as a component in protective coatings on cold-rolled steel, considerably reducing oxygen diffusion from the solution to the surface of the protected material. Figure 1 shows a scratched area of the VEP/SAP/VEP coating with $5 \mathrm{wt} \%$ of SAP before and after a 6-hour corrosion test [9]. A large number of spherical particles are observed on the scratched surface of the substrate after the test. The particles consist most likely of the SAP released from the SAP-mixed layer.

In the case of coatings based on epoxy resins containing maleimides (e.g. 1,1(methylenedi-4,1-phenyl)bismaleide or $N, N^{\prime}$-(1,3-phenylenedi)maleimide)) and thiols (e.g. pentaerythritol(3-mercaptopropionate)), self-healing takes place in two ways depending on the location in the crack in which damage occurred. Figure 2 [17] illustrates the differences between self-repairing taking place at the crack interface and the one taking place in the bulk area of the crack. Maleimides can react with the residual amines present in the epoxy matrix (they are used as hardeners) or with thiols [16]. The catalysts of the latter reaction are tertiary amines which are introduced into the polymer, as a component aiding the self-repair process.

Epoxy resin with poly(o-phenylenediamine) nanotubes was applied by brushing it onto mild steel samples. The PoPD nanotubes were used as a pigment. Their presence causes the passivation of the substrate when the coating is damaged. The potential difference which then appears at the substrate/electrolyte and PoPD/electrolyte interfaces forces the reduction of PoPD, leading to the oxidation of the metal. Thanks to the oxidation reaction, in which atmospheric oxygen or the oxygen dissolved in the 

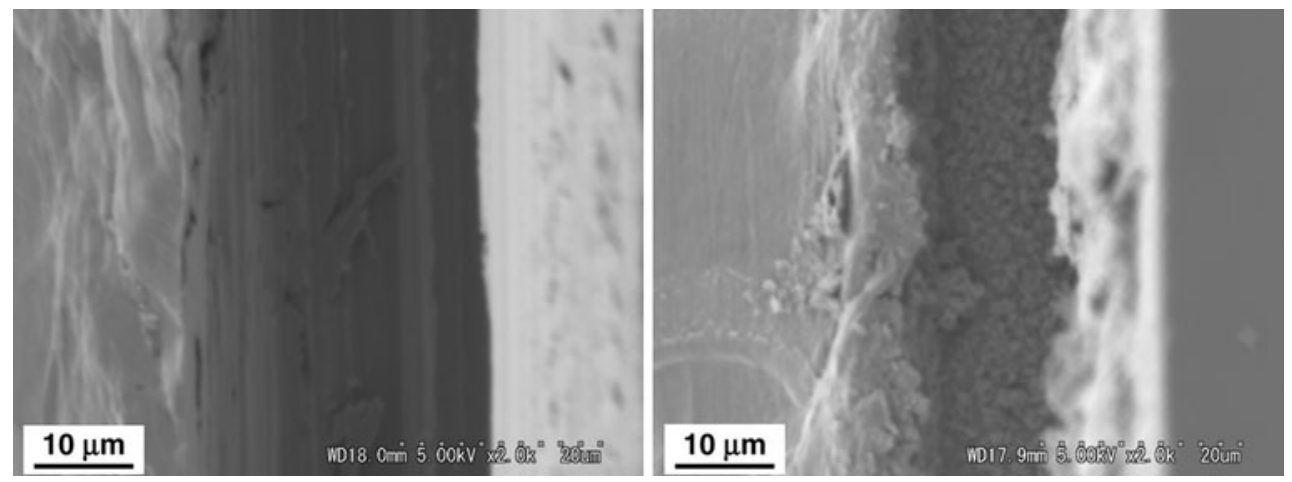

Fig. 1 The scratched part of the VEP/SAP/VEP coating with 5 wt $\%$ of SAP before and after a 6 h corrosion test. Reprinted from Ref. [8] with permission from Elsevier

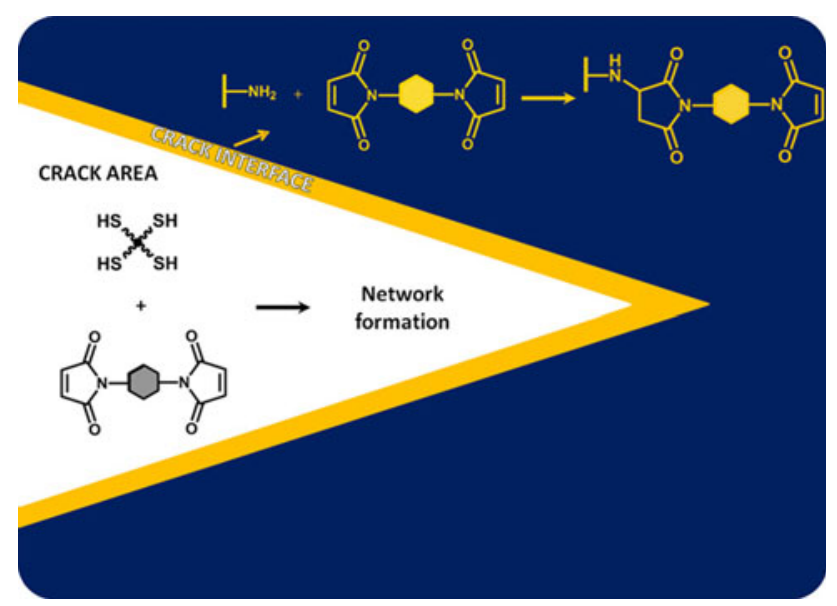

Fig. 2 Schematic illustration of a crack in the epoxy coating. Reprinted from Ref. [15] with permission from Elsevier

electrolyte can be the oxidizer, the PoPD returns to its original state [19].

Vinylester polymer coatings containing $\mathrm{TiO}_{2}$ particles can be used to protect aluminium alloy 5083 against corrosion. In the case of damage to the coating, bisphenol A (BPA) (one of the chemical precursors of vinylester polymer) is released. BPA reacts with aluminium, forming a barrier coating in the defective place [10]. A schematic representation of the self-healing effect of the $\mathrm{TiO}_{2}$ particle-polymer composite coating is shown in Fig. 3 [10]. The rutile particles present in the coatings serve as containers for BPA.

In a coating composed of $5 \mathrm{E} 2 \mathrm{~N}$ and $\mathrm{RGC}$ nanoparticles, the self-healing mechanism is based on ring-opening metathesis polymerization (ROMP) [8]. The reaction is induced by a thermal stimulus. The polymerization is stimulated by the Grubbs catalyst (metallo-organic compounds being effective catalysts of the metathesis of olefins). However, the ruthenium Grubbs catalyst is neither a cheap nor a stable compound. RGC has limited durability

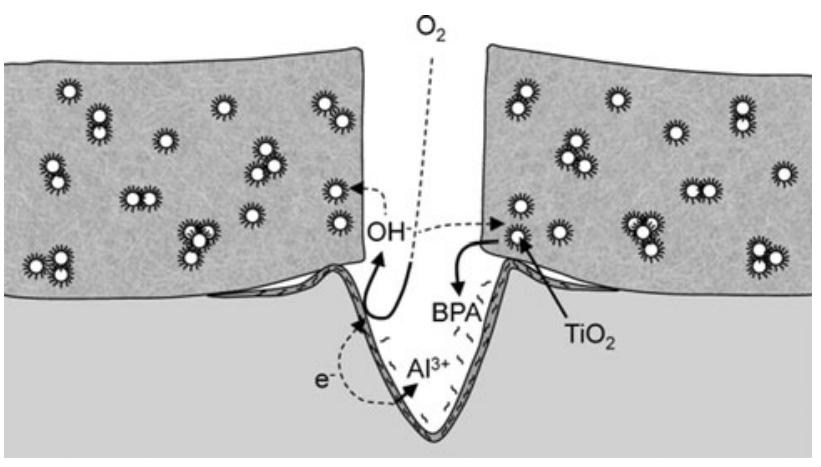

Fig. 3 Schematic representation of the self-healing effect of the $\mathrm{TiO}_{2}$ particle-polymer composite coating. Reprinted from Ref. [9] with permission from John Wiley and Sons

due to the prolonged exposure to oxygen, moisture and the amine curing agent. Furthermore, the catalyst is toxic [16].

Macromolecular compounds which contain fluorine are used to protect magnesium alloys. Fluoropolymers are characterized by good thermal and chemical stability. The most attractive property of such coatings is water repellence, which plays a vital part in corrosion protection. An example here is poly(vinylidene fluoride) coating. The proposed self-healing mechanism is based on interfacial reactions between magnesium hydroxide (a corrosion product) and the polymer. The corrosion product is converted into magnesium fluoride which acts as a protective layer [7].

Another example of a protective fluoropolymer coating is a coating made of a copolymer consisting of polychlorotrifluoroethylene (PCTFE) and vinylether. The self-healing ability of this fluorine resin coating can be improved by adding some metal (e.g. titanium or zinc) powder [20].

A poly(HFBMA-co-ITEGMA) copolymer is used to produce coatings on aluminium alloys. Owing to the properties of the two polymer components, the coating consists of two layers: 
- HFBMA, which makes a good water barrier, is located on the solid-air interface;

- ITEGMA, because of its strong polarity, is located on the solid-substrate interface.

The self-healing mechanism (called a zipper-like mechanism) is illustrated in Fig. 4 [6]. When the coating is damaged, the isocyanate groups react with the water particles present in air. A stable urea cross-link is formed.

In the literature, one can find descriptions of more environmentally friendly coatings based on biopolymers. An example here is a coating containing chitosan, functioning as a prelayer reservoir of the corrosion inhibitor, used to protect aluminium alloys [14, 21]. Cerium in the form of $\mathrm{Ce}\left(\mathrm{NO}_{3}\right)_{3}$ is used as an additive improving the selfrepair properties of this coating. Cerium(III) nitrate is known to be a proven corrosion inhibitor for aluminium alloys. $\mathrm{Ce}^{3+}$ cations are released from the chitosan matrix and corrosion pits are passivated owing to the precipitation of cerium hydroxides.

Active corrosion protection can be provided for aluminium alloys by depositing polyelectrolyte multilayers on them. The self-healing properties are based on the selfcuring attributes of the coatings. The protective action of such a system can be described as follows [22]:

- polyelectrolytes ensure pH-buffering stability and can keep the $\mathrm{pH}$ on metal surfaces stable in corrosive media;

- polyelectrolytes are relatively mobile and show a tendency to seal and eliminate any mechanical damage to the coating.

Protective coatings can also be obtained through deposition from a strong negative polyelectrolyte-poly(styrene sulphonate) (PSS) and from a weak positive polyelectrolyte-poly(ethyleneimine) (PEI) [23]. Their protective
Fig. 4 Illustration of selfhealing zipper-like mechanism. Reprinted from Ref. [6] with permission from Elsevier (a)
1

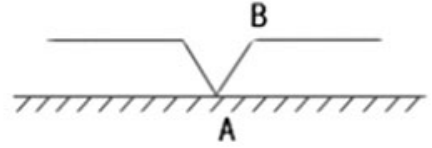

2

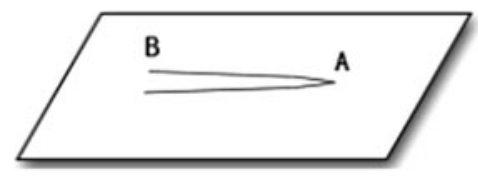

3
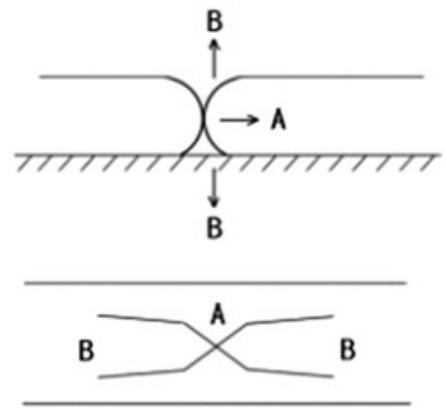

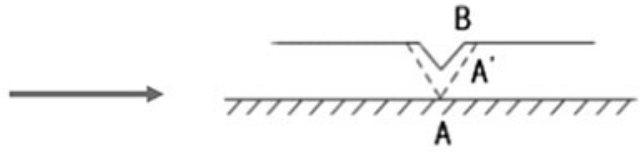

A
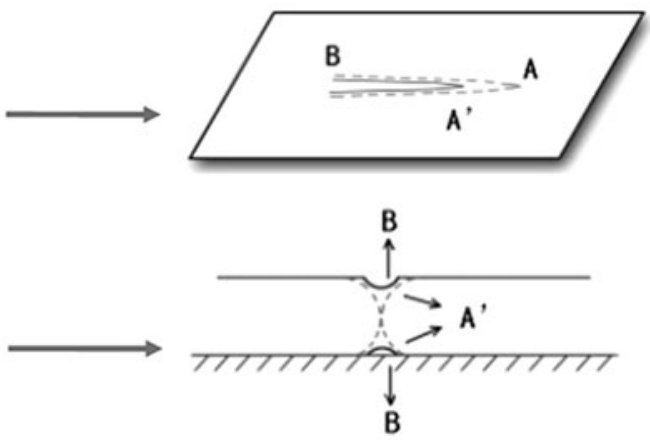
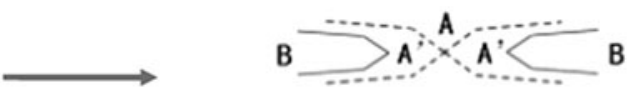

(b)

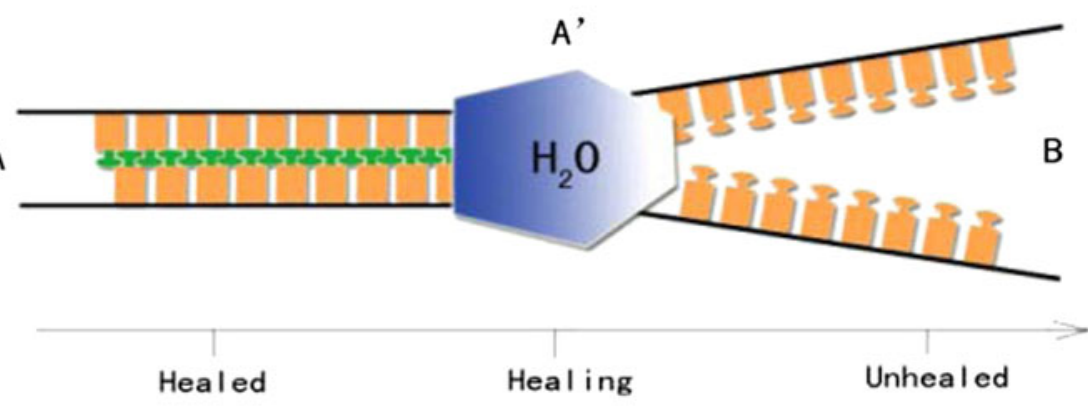

$-\mathrm{NH}-\mathrm{CO}-\mathrm{NH}-$ 
properties can be improved by introducing 8-hydroxyquinoline (8HQ). This compound prevents the adsorption of chloride ions forming an insoluble chelate of aluminium [22]. There are also coatings consisting of PEI and poly(allylamine hydrochloride) and 2-(benzothiazol-2ylsulfanyl)succinic acid [11]. A schematic mechanism of corrosion protection in their case is shown in Fig. 5 [23].

A large number of polymers owe their self-repair properties to the corrosion-inhibiting compounds introduced into the matrix, such as silyl ester (octyldimethylsilyloleate), 8-hydroxyquinoline, calcium(II) and zinc(II)exchanged pigments, phenylphosphonic acid and sodium benzoate [12, 13, 24-26].

\section{Coatings containing micro- or nanocapsules}

The addition of corrosion inhibitors directly to coatings, which is one of the possibilities of protecting a metallic substrate against the action of a corroding medium, has several shortcomings, such as coating integrity degradation, inhibitor deactivation or undesired leaching. The encapsulation of corrosion inhibitors and the introduction of the capsules into the matrix of the coating are considered

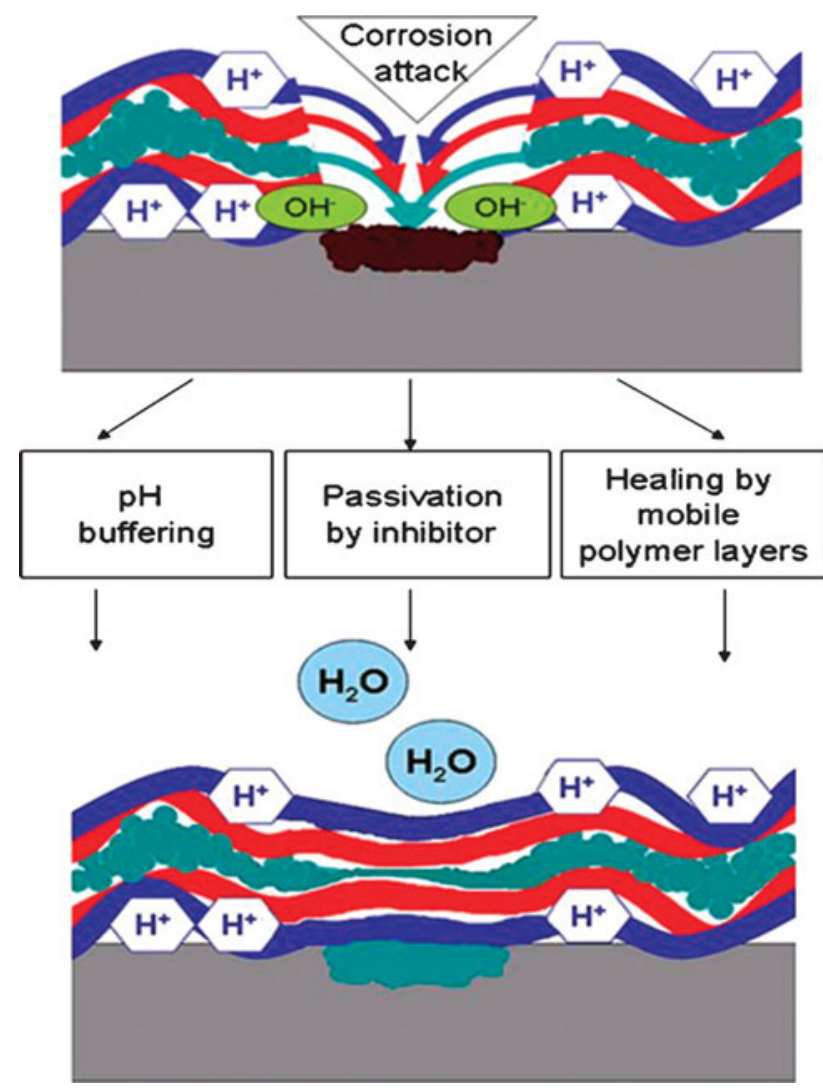

Fig. 5 Self-healing mechanism of polyelectrolyte multilayers. Reprinted from Ref. [25] with permission from John Wiley and Sons to be a viable way of avoiding the above disadvantages [27]. There are literature reports corroborating the more beneficial effect of inhibitor encapsulation on the quality of coatings in comparison with the cases in which an inhibitor is added directly to the coating [28]. A major advantage of such coatings is the controlled release of the capsules' content and the widely adjustable self-repair properties. There are many mechanisms responsible for the changes in the envelope of the capsule, resulting in the exposure of its core. They consist of activation with light of different wavelengths, a change in the $\mathrm{pH}$, a thermal pulse and magnetic, chemical, electrical and biological induction [29]. The self-repair action of coatings with micro/nanocapsules is based on desorption controlled release, $\mathrm{pH}$ controlled release, the ion-exchange control of release and release under mechanical rapture [30].

There are four principal methods of obtaining micro/ nanocapsules [29, 31]: emulsification, layer-by-layer (LBL) assembly, coacervation and internal phase separation. Figure 6 schematically shows how a capsule is created using the particular methods [29]. As the building material, the following are used: poly(urea-formaldehyde) (PUF) [32-35], melamine-urea-formaldehyde (MUF) [35, 36], phenol-formaldehyde [37], epoxy resin [38, 39], methylene diphenyl diisocyanate (MDI) [40], poly(methyl methacrylate) (PMMA) [41, 42], polystyrene [32, 41], poly(allylamine) [43], polyvinyl alcohol (PVA) [43, 44], polyurethane [40], polyphenol, amphiphilic block copolymers (polypyrrolidones, poly(ethylene oxide) [31], poly(caprolactone)) [31, 32], cerium molybdate [45], zinc and aluminium nitrate [46, 47], silica [27, 32, 48-50], silver [42], gold [51], copper(II) sulphide [51], $\gamma$ - $\mathrm{AlO}(\mathrm{OH})$ [51], tin(IV) oxide [51] and titania oxides [42, 52, 53] and $\mathrm{CaCO}_{3}$ microbeads [54]. The capsule material and the way of preparing capsules affect their shape and size. The effect of the rate of agitation during the synthesis of the containers has been described in the literature. An increase in the agitation rate results in a reduction in capsule size [40, 55]. The diameter of capsules significantly decreases also as the concentration of the surfactant (gum arabic) increases, which is ascribed to the influence of surfactant concentration (before the critical micelle concentration is reached) on the interfacial tension of the emulsion media [40]. In most cases, the capsules have a spherical shape. Tubular capsules can be obtained from, for example, $\mathrm{SiO}_{2}$ and PMMA [56].

Polymer capsules are often coated with a layer of inorganic compounds, e.g. $\mathrm{SiO}_{2}$ or $\mathrm{TiO}_{2}$, and then annealed at $500{ }^{\circ} \mathrm{C}$. The only capsule materials remaining after annealing are oxides [24, 48]. Halloysite nanotubes and boehmite nanoparticles are employed as reservoirs for corrosion-inhibiting compounds [57-59]. Cerium cations [58, 60-62], 8-hydroxyquinoline [48, 57], benzotriazole 


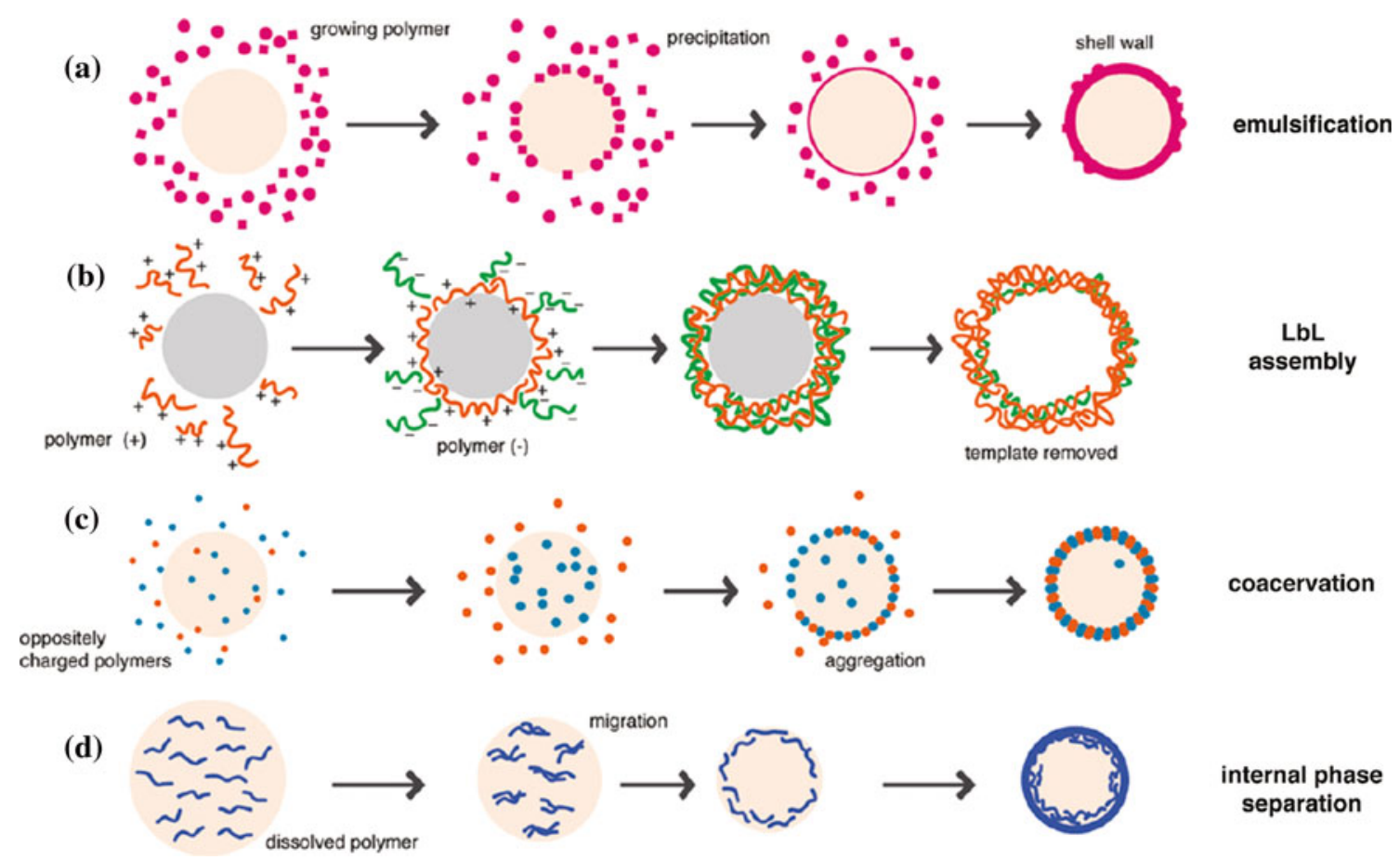

Fig. 6 Schematic illustrations of capsules forming. Reprinted with permission from Ref. [30]. Copyright 2013 American Chemical Society

[57, 62], 2-mercaptobenzothiazole (MBT) [45, 48, 49, 63, 64], mercaptobenzimidazole (MBI) [63], dicyclopentadiene (DCPD), alkoxysilanes [65], silyl ester [24], linseed oil [37, 44, 66], hexamethylene diisocyanate (HDI) [40], triethanolamine (TEA) [41], monomers and catalysts for ROMP [67], magnesium ions [68], chromium(III) and cerium(IV) oxides [34] and cerium(III) chloride [60, 69] are used as corrosion inhibitors. The action mechanisms connected with the particular compounds are presented in Table 1. In all the cases, micro/nanocontainers are first filled with an active agent and then dispersed in the whole coating matrix. The capsules are filled in different ways, e.g. by agitating the suspension of capsules and fillers, also under reduced pressure, the soaking of capsules in inhibitor solution and by applying the LBL deposition procedure $[27,54,56,70]$. In the case of soaking encapsulation, different inhibitor retention mechanisms can be distinguished. The ion-exchange mechanism and adsorption on the porous surface of capsules are proposed for respectively cerium ions and organic inhibitors. In the considered example, $\mathrm{CaCO}_{3}$ microbeads were used as containers [54]. Micro/nanocontainers can be incorporated into a polymeric coating [35, 54, 68, 71], less often into a sol-gel coating $[27,72]$, and sporadically into a metallic coating, e.g. one based on electrochemical nickel [73]. The anticorrosive properties of coatings are affected by the nanocontainers' concentration in the coating matrix and the nanocontainer position. The amount of the inhibitor should be sufficient to assure a satisfactory degree of protection and small enough to preserve the barrier properties of the coating. Studies into the effect of the location of capsules in the coating have shown that coatings with containers located close to the metal surface provide better active protection against corrosion than coatings in which the coating layer with capsules is separated from the protected surface by an additional layer devoid of capsules [27]. The effect of the distribution of the encapsulated corrosion inhibitor in the coating matrix on the release of the inhibitor was determined through a theoretical analysis [74]. The obtained mathematical model highlights the significant effect of the concentration and distribution of capsules on the release kinetics.

Despite their clear advantages, such coatings have one major drawback: self-healing is possible only in the case of the first damage to the coating. Moreover, the incorporated particles may adversely affect the adhesion of the coating to the substrate $[31,46,67,75,76]$. In order to minimize this adverse effect, the micro/nanocontainer material should be matched to the coating material. For example, silica nanocontainers may be unsuitable for polymer-based coatings because of the differences in the mechanical properties. In such cases, polymer nanocontainers are more suitable [67]. Other major factors determining the quality of the coating are the compatibility and adhesion between the capsules and the coating matrix. An ideal solution for a slightly alkaline coating made of epoxy resin seems to be capsules with an epoxy-amine shell. As opposed to PUF or MUF capsules which require an acidic medium, capsules 
Table 1 Selected inhibitors used as micro- and nanocapsule filling and their action mechanism

\begin{tabular}{llll}
\hline Inhibitor & Substrate & Action mechanism \\
\hline Ce $^{3+}$ & AA2024 & Formation of cerium hydroxides & Ref. \\
TEA & Steel & Formation of passive layer & [60] \\
HDI & Steel & Reaction with water resulting in barrier layer formation \\
Silyl ester & AA2024 & Formation of hydrophobic barrier layer & [34] \\
Linseed oil & Glass, mild steel & Inhibitor oxidation reaction resulting in barrier layer formation \\
Alkoxysilanes & AA2024 & Reaction of alkoxysilanes with water resulting in hydrophobic \\
MBT & AA2024, galvanized steel & Passive layer formation on damaged substrate surface \\
8HQ & AA2024 & Formation of complexes with Al and formation of barrier layer \\
BTA & AA2024 & Formation of complexes with Cu (being alloy and barrier \\
& & layer component) and formation of barrier layer
\end{tabular}

with an epoxy-amine shell are formed in an alkaline medium. Furthermore, when preparing microcapsules with an epoxy-shell wall, there is no need to adjust the acidity or alkalinity of the system [35]. Another measure improving the tribological properties of the coatings is the elimination of the self-healing process catalyst constituting an additional separated phase in the coating matrix. Instead of a self-healing system consisting of a polymer and a catalyst necessary for polymerization, one can use oxidative healing agents, e.g. drying oils, since they do not require the use of a catalyst [55]. A similar solution is the encapsulation of magnesium ions. Then, the self-repair process is possible owing to $\mathrm{Mg}(\mathrm{OH})_{2}$ precipitation [68].

Micron-sized gel particles (microgel), e.g. polyurea microgel particles with 2-methylbenzothiazole (MeBT), can constitute the 'active' part of a self-healing coating system. Then, the liquid corrosion inhibitor is entrapped in the solid matrix. This way of obtaining self-repairing coatings is considerably simpler than that of producing coatings with containers [77].

\section{Hybrid oxide coatings}

Self-healing hybrid oxide coatings are produced using the sol-gel technique [78-82], less often by electrodeposition [83], or using plasma techniques [84]. Alcoholates or salts of various metals and silicon are the substrate. Many of such precursors are commercially available. Coatings produced using the sol-gel technique can be composed of several oxides whereby various protective properties can be obtained. In the literature, one can find descriptions of coatings containing $\mathrm{SiO}_{2}, \mathrm{ZrO}_{2}, \mathrm{TiO}_{2}$, as well as a cerium addition [78, 79, 81, 85-96]. Such coatings are used as a substitute for the chromate-based system, mainly to protect steel or aluminium alloys. In order to obtain self-healing properties, the coatings are doped with corrosion inhibitors. Lanthanides ions, benzotriazoles, 8-hydroxyquinoline, propargyl alcohol or red mud (waste from the production of aluminium by the Bayer method, consisting of iron and titanium oxides and silicon compounds) is commonly used for this purpose [85, 93-97]. Also, hybrid coatings are produced [82, 85, 91, 92, 98-100]. The inorganic groups form covalent bonds with the native oxide film present on the metallic substrate, whilst the organic groups contact the painting systems. Such a 'molecular bridge' improves the adhesion of the additional organic layers (paints, adhesives) to the protected substrate. Besides a metal oxide or silica, hybrid coatings contain organic compounds, such as methacrylates, alkylsilanes and poly(ethylene imine). Thanks to the organic fractions, a more ductile system with less stress tensions and thicker than the one containing traditional inorganic fractions is obtained. PEI acts as a cross-linking agent for hybrid coating formation and as a solubilizer of the organic corrosion inhibitor. These coatings are enriched with substances improving corrosion resistance, such as cerium incorporated into montmorillonite nanoparticles, MBT or 2-mercaptobenzimidazole (MBI) [92, 99]. The self-healing of the coating by means of lanthanides ions takes place as a result of the diffusion of these ions to the substrate surface and the formation of an insoluble layer of oxides and hydroxides (a cathodic inhibitor) [78, 79, 85-87]. The effectiveness of inhibiting action of $\mathrm{Ce}$ (III) and $\mathrm{Ce}$ (IV) ions is comparable with that of the $\mathrm{Cr}(\mathrm{VI})$ ion [101]. The presence of lanthanide ions sometimes may contribute to a reduction in the efficacy of such coatings because of their high porosity resulting in inhibitor loss. The layers enriched with red mud acquire self-repair properties after annealing at a temperature of about $900{ }^{\circ} \mathrm{C}$, during which the compounds contained in the mud undergo phase changes inducing the formation of aluminium oxide characterized by increased stability [93]. Benzotriazole is adsorbed on the metal surface and acts as an anodic 
inhibitor [94]. Contrary to [94], some authors report that the presence of BTA in the sol-gel coating negatively affects the barrier properties of sol-gel films and does not provide adequate corrosion protection [97]. Propargyl alcohol can positively influence the barrier properties of the coating [95]. MBT and MBI form a thin adsorption layer on the damaged metallic surface [99]. 8HQ as a cathodic inhibitor for aluminium, in neutral chloride solution, forms poorly soluble chelate complexes with aluminium [97].

An effective solution eliminating the reported adverse effect of an inhibitor addition on the quality of the coating consists of applying first a porous layer of $\mathrm{TiO}_{2}$ (made up of rutile and anatase phases) directly to the substrate surface. The layer serves as a reservoir for the corrosion inhibitor. Subsequently, this layer is covered with a sol-gel coating consisting of zirconium oxide and organosiloxane $[52,62]$. The nanostructured $\mathrm{TiO}_{2}$ film is a desirable protective material not only because of its high resistance to the action of chemical compounds but also because of its unique photoelectrochemical properties. Owing to them, it can be used, for example, to build solar cells. According to some literature reports, $\mathrm{TiO}_{2}$ coatings can be used for the photogenerated cathodic protection of metals under ultraviolet (UV) illumination. When such a coating is exposed to UV irradiation, photogenerated electrons are introduced into the metallic substrate from this semiconductor and adjust its Fermi level. As a result, the metal potential is shifted towards more negative values and ultimately to the metal thermodynamic stability value. In this way, it can be protected against corrosion. The advantage of this solution is the absence of coating wear in the course of the protection process. In order to ensure active protection in conditions of limited access to UV radiation, the coatings are doped with chromium(III) ions. This transition metal contributes to an increase in the photocatalytic activity of titanium(IV) oxide [102].

The corrosion resistance of hybrid oxide coatings depends also on the conditions in which they are applied. In the case of silica-organic coatings, as the concentration of the silicate solution increases, their protective properties deteriorate due to high porosity. An improvement in their protective properties can be achieved through additional curing [103] or by applying a subcoating which by forming Si-O-M (M-a metal constituent of the substrate) bonds perfectly adheres to the substrate surface [104]. Curing is used to induce better cross-linking of the layer. The structure of a silane film is shown in Fig. 7. The coatings provide good corrosion protection owing to the hydrophobicity of the layer [105]. Beneficial effects are obtained by introducing silica-organic $\mathrm{Al}_{2} \mathrm{O}_{3}, \mathrm{CeO}_{2}, \mathrm{TiO}_{2}$ or $\mathrm{SiO}_{2}$ particles into the coatings in the course of their deposition [106].

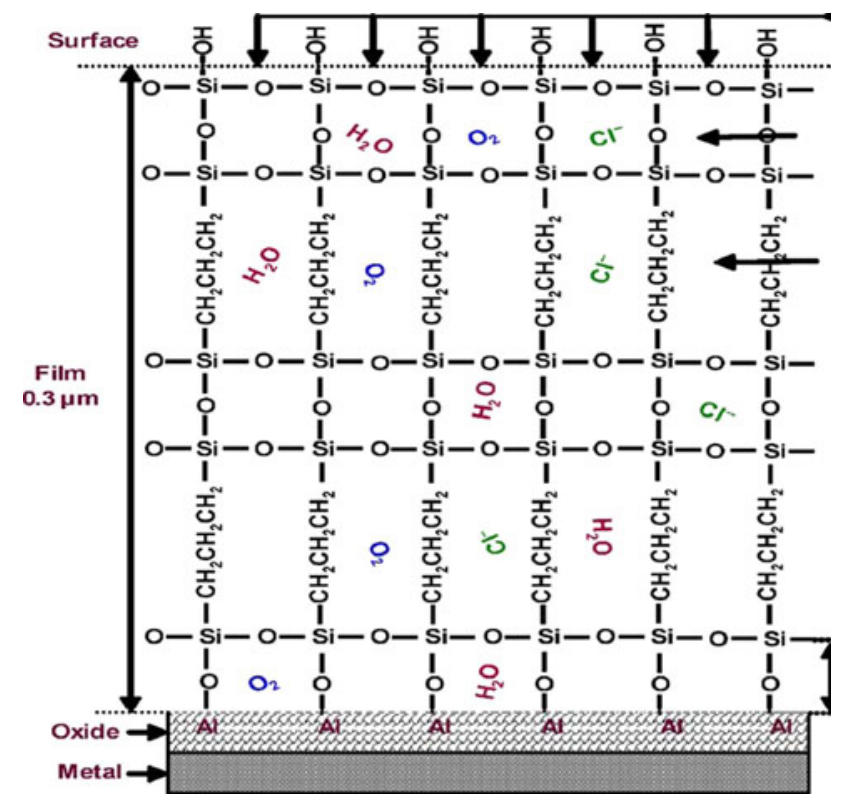

Fig. 7 Structure of silane film. Reprinted from Ref. [72] with permission from Elsevier

\section{Other self-healing coatings}

In the literature, one can find information about the selfrepair properties of conversion coatings [107-112]. Such coatings were deposited on, amongst others, a zinc electrode by treatments in a solution containing cerium(III) nitrate, sodium phosphate and zinc nitrate [107-109]. Coatings containing chromium(III) and chromium(VI), doped with nickel and cobalt ions, are described in [112]. The descriptions suggest that cobalt ions may contribute towards the oxidation of $\mathrm{Cr}(\mathrm{III})$ to $\mathrm{Cr}(\mathrm{VI})$ or that nickel and cobalt cations take part in the formation of a barrier coating. Another self-healing conversion coating is a silicate coating (deposited from a $\mathrm{SiO}_{2}$ and $\mathrm{Na}_{2} \mathrm{O}$ solution) on galvanized steel. In this case, the self-healing effect is achieved owing to the ability of silicate anions to migrate and react with the substrate, as a result of which a new conversion coating containing $\mathrm{Zn}, \mathrm{O}$ and $\mathrm{Si}$ forms [113]. Vanadia-based coatings prevent damage by forming an oxide layer enriched with this metal [110, 111, 114]. Conversion coatings based on potassium stannate are used to protect magnesium alloys. They are characterized by higher resistance to pitting corrosion owing to the formation of a tin oxide-rich magnesium hydroxide layer preventing oxygen diffusion to the alloy surface [115]. In the literature, one can also find descriptions of coatings containing fluoro-organic compounds, which are used to protect zinc [116]. The compounds represent several types of fluoro-organic combinations with different terminal groups $(\mathrm{COOH}, \mathrm{OH}, \mathrm{COF})$. The self-healing ability of such coatings consists of forming a barrier film on the damaged 
surface. An example of a self-healing metallic coating is the electrochemically produced zinc coating with polyethylene oxide- $b$-polystyrene $\left(\mathrm{PEO}_{113}-b\right.$ - $\left.\mathrm{PS}_{218}\right)$ nanoaggregates. It owes it self-healing properties to the amphiphilic polymer which in a medium containing chloride ions has an ability to reversibly shrink and swell [117]. Composite coatings containing nanocontainers in a nickel matrix are produced using the electrochemical method [73]. Coatings based on magnesium alloy AZ31, consisting of titanium(IV) oxide and casein, deposited from a casein solution with $1 \mathrm{wt} \%$ of $\mathrm{TiO}_{2}$ by the immersion method are mentioned. Self-healing in this case is induced by a change in the $\mathrm{pH}$. Depending on the hydrogen ions concentration, casein forms agglomerates or is dispersed. An increase in the $\mathrm{pH}$ near a coating defect, caused by the digestion of the alloy, contributes towards the release of casein from the coating, which in turn entails the displacement of $\mathrm{TiO}_{2}$ particles which diffuse to the damaged place, forming a barrier layer there [118]. This kind of coating deserves special attention because of the use of the naturally occurring compound as the inhibitor. Ceramic materials ( $\mathrm{TiC} / \mathrm{Al}_{2} \mathrm{O}_{3}$ and $\mathrm{Ti}_{2} \mathrm{AlC}$ ) are used for self-healing coatings. In this case, self-healing is activated by an increase in temperature, resulting in the oxidation of the coating components and in the filling of the defects by titanium and aluminium oxides [119, 120].

\section{Self-healing process investigation}

The performance of a self-healing coating in corrosive media can be investigated using various techniques, such as electrochemical impedance spectroscopy (EIS), the scanning vibrating electrode technique (SVET) and the scanning ion-selective electrode technique (SIET) [45, 50, 53, 57, 58, 62, 63, 96]. EIS can be used to estimate coating degradation and corrosion kinetics even when the time of coating exposure in a corrosive medium is not long. This technique is usually aided by SVET $[45,50,62,96,121]$ or localized impedance spectroscopy (LEIS) [122]. In some cases, however, the properties of self-repairing coatings are assessed solely on the basis of the results obtained by EIS [55, 102]. The SVET supplies information on corrosion initiation in a small area. SVET consists of non-intrusive scanning and vibrating probe measurement. In addition, the electric field generated in a plane above the electrochemically active surface is being mapped, whereby the local electrochemical activity of the coating can be recorded and quantified in real time [121]. This technique is particularly useful for observing the action of corrosion inhibitors in self-healing coatings. The scanning ion-electrode technique is used to map local changes in $\mathrm{pH}$ on the coating surface. The combined use of the electrochemical techniques mentioned above gives a holistic picture of the self-healing ability [45]. X-ray photoelectron spectroscopy (XPS) and electron-probe microanalysis (EPMA) are used to study the self-repairing mechanism [108]. XPS allows analyses of the chemical composition of the surface in places where it has been mechanically damaged. EPMA supplies information on the migration of ions in the vicinity of a coating scratch. Microscopic techniques are also used to assess the self-healing properties of coatings. For this purpose, the coating is cut, immersed in a corrosive solution and the place of the cut is examined at fixed time intervals using optical microscopy, scanning electron microscope (SEM), atomic force microscopy (AFM) or scanning Kelvin probe force microscopy (SKPFM) [32, 37, 38, 40, 102, 115]. The scanning electrochemical microscope (SECM) is used a tool enabling one to evaluate the self-repairing properties of coatings [44]. Using this technique, one can not only acquire microscopical data from the surface affected by corrosion but also measure local differences in electrochemical reactivity. Furthermore, the release of metal ions at anodic sites and the consumption of oxygen at cathodic sites can be monitored. A major advantage of SECM is the ability to monitor both insulating and conducting surfaces.

\section{Conclusions}

The production of intelligent protective coatings has been the subject of numerous studies. The functionality of such a coating comes down to the removal of its defects arising in the course of service. Various coating self-healing concepts are considered. In the case of anti-corrosion coatings, mechanisms based on the release of a corrosion inhibitor, the swelling of macromolecular compounds or the oxidation and passivation of the protected substrate are mentioned. Considering the wide range of available materials, the number of potential combinations seems to be unlimited. Computer simulations, which make it possible to model the phenomena taking place in the course of selfhealing, are helpful in designing self-healing coatings.

Open Access This article is distributed under the terms of the Creative Commons Attribution License which permits any use, distribution, and reproduction in any medium, provided the original author(s) and the source are credited.

\section{References}

1. Aïssa B, Therriault D, Haddad E, Jamroz W (2012) Adv Mater Sci Eng 2012:1. doi:10.1155/2012/854203

2. Karpakam V, Kamaraj K, Sathiyanarayanan S, Venkatachari G, Ramu S (2011) Electrochim Acta 56:2165. doi:10.1016/j. electacta.2010.11.099

3. Arefinia R, Shojaei A, Shariatpanahi H, Neshati J (2012) Prog Org Coat 75:502. doi:10.1016/j.porgcoat.2012.06.003 
4. Akid R, Gobara M, Wang H (2011) Electrochim Acta 56:2483. doi:10.1016/j.electacta.2010.12.032

5. Kowalski D, Ueda M, Ohtsuka T (2010) J Mater Chem 20:7630. doi:10.1039/c0jm00866d

6. Zhang Z, Hu Y, Liu Z, Guo T (2012) Polymer 53:2979. doi:10. 1016/j.polymer.2012.04.048

7. Da Conceicao TF, Scharnagl N, Dietzel W, Hoeche D, Kainer KU (2011) Corros Sci 53:712. doi:10.1016/j.corsci.2010.11.001

8. Aïssa B, Nechache R, Haddad E, Jamroz W, Merle PG, Rosei F (2012) Appl Surf Sci 258:9800. doi:10.1016/j.apsusc.2012.06.032

9. Yabuki A, Okumura K (2012) Corros Sci 59:258. doi:10.1016/j. corsci.2012.03.007

10. Yabuki A, Urushihara W, Kinugasa J, Sugano K (2011) Mater Corros 62:907. doi:10.1002/maco.201005756

11. Grigoriev DO, Köhler K, Skorb E, Shchukin DG, Möhwald H (2009) Soft Matter 5:1426. doi:10.1039/b815147d

12. Williams G, Geary S, McMurray HN (2012) Corros Sci 57:139. doi:10.1016/j.corsci.2011.12.024

13. Yabuki A, Nishisaka T (2011) Corros Sci 53:4118. doi:10.1016/ j.corsci.2011.08.022

14. Carneiro J, Tedim J, Fernandes SCM, Freire CRS, Silvestre AJD, Gandini A, Ferreira MGS, Zheludkevich ML (2012) Prog Org Coat 75:8. doi:10.1016/j.porgcoat.2012.02.012

15. Yuan J, Fang X, Zhang L, Hong G, Lin Y, Zheng Q, Xu Y, Ruan Y, Weng W, Xia H, Chen G (2012) J Mater Chem 22:11515. doi:10.1039/c2jm31347b

16. Billiet S, Van Camp W, Hillewaere XKD, Rahier H, Du Prez FE (2012) Polymer 53:2320. doi:10.1016/j.polymer.2012.03.061

17. Feng W, Patel SH, Young MY, Zunino JL III, Xanthos M (2007) Adv Polym Technol 26:1. doi:10.1002/adv

18. Cho SH, White SR, Braun PV (2009) Adv Mater 21:645. doi:10. 1002/adma.200802008

19. Siva T, Kamaraj K, Karpakam V, Sathiyanarayanan S (2013) Prog Org Coat 76:581

20. Yabuki A, Yamagami H, Noishiki K (2007) Mater Corros 58:497. doi:10.1002/maco.200604041

21. Zheludkevich ML, Tedim J, Freire CSR, Fernandes SCM, Kallip S, Lisenkov A, Gandini A, Ferreira MGS (2011) J Mater Chem 21:4805. doi:10.1039/c1jm10304k

22. Andreeva DV, Fix D, Möhwald H, Shchukin DG (2008) Adv Mater 20:2789. doi:10.1002/adma.200800705

23. Andreeva DV, Fix D, Möhwald H, Shchukin DG (2008) J Mater Chem 18:1738. doi:10.1039/b801314d

24. García SJ, Fischer HR, White P, Mardel J, González-Garcia Y, Mol JMC, Hughes AE (2011) Prog Org Coat 70:142. doi:10. 1016/j.porgcoat.2010.11.021

25. Williams G, Gabriel A, Cook HNM A (2006) J Electrochem Soc 153:B425

26. Tüken T, Yazıcı B, Erbil M (2006) Appl Surf Sci 252:2311. doi:10.1016/j.apsusc.2005.04.004

27. Borisova D, Möhwald H, Shchukin DG (2013) ACS Appl Mater \& Interfaces 5:80. doi:10.1021/am302141y

28. Kartsonakis IA, Balaskas AC, Koumoulos EP, Charitidis CA, Kordas G (2012) Corros Sci 65:481. doi:10.1016/j.corsci.2012. 08.052

29. Esser-Kahn AP, Odom SA, Sottos NR, White SR, Moore JS (2011) Macromolecules 44:5539. doi:10.1021/ma201014n

30. Zheludkevich ML, Tedim J, Ferreira MGS (2012) Electrochim Acta 82:314. doi:10.1016/j.electacta.2012.04.095

31. Shchukin DG, Zheludkevich ML, Möhwald H (2006) J Mater Chem 16:4561. doi:10.1039/b612547f

32. Mauldin TC, Kessler MR (2010) Int Mater Rev 55:317

33. Nesterova T, Dam-Johansen K, Pedersen LT, Kiil S (2012) Prog Org Coat 75:309. doi:10.1016/j.porgcoat.2012.08.002

34. Selvakumar N, Jeyasubramanian K, Sharmila R (2012) Prog Org Coat 74:461. doi:10.1016/j.porgcoat.2012.01.011
35. Liu X, Zhang H, Wang J, Wang Z, Wang S (2012) Surf Coat Technol 206:4976. doi:10.1016/j.surfcoat.2012.05.133

36. Nesterova T, Dam-Johansen K, Kiil S (2011) Prog Org Coat 70:342. doi:10.1016/j.porgcoat.2010.09.032

37. Jadhav RS, Hundiwale DG, Mahulikar PP (2011) J Appl Polym Sci 119:2911. doi:10.1002/app

38. Yang Z, Wei Z, Liao L, Wang H, Li W (2011) Physics Procedia 18:216

39. Zhao Y, Zhang W, Liao L, Wang S, Li W (2012) Appl Surf Sci 258:1915. doi:10.1016/j.apsusc.2011.06.154

40. Huang M, Yang J (2011) J Mater Chem 21:11123. doi:10.1039/ c1jm10794a

41. Choi H, Song YK, Kim KY, Park JM (2012) Surf Coat Technol 206:2354. doi:10.1016/j.surfcoat.2011.10.030

42. Shchukin DG, Grigoriev DO, Möhwald H (2010) Soft Matter 6:720. doi:10.1039/b918437f

43. Shchukin DG, Möhwald H (2011) Chem commun (Camb) 47:8730. doi:10.1039/c1cc13142g

44. Pilbáth A, Szabó T, Telegdi LN J (2012) Prog Org Coat 75:480. doi:10.1016/j.porgcoat.2012.06.006

45. Montemor MF, Snihirova DV, Taryba MG, Lamaka SV, Kartsonakis IA, Balaskas AC, Kordas GC, Tedim J, Kuznetsova A, Zheludkevich ML, Ferreira MGS (2012) Electrochim Acta 60:31. doi:10.1016/j.electacta.2011.10.078

46. Tedim J, Poznyak SK, Kuznetsova A, Raps D, Hack T, Zheludkevich ML, Ferreira MGS (2010) ACS Appl Mater \& Interfaces 2:1528. doi:10.1021/am100174t

47. Zheludkevich ML, Poznyak SK, Rodrigues LM et al (2010) Corros Sci 52:602. doi:10.1016/j.corsci.2009.10.020

48. Haase MF, Grigoriev DO, Möhwald H, Shchukin DG (2012) Adv Mater 24:2429. doi:10.1002/adma.201104687

49. Maia F, Tedim J, Lisenkov AD, Salak AN, Zheludkevich ML, Ferreira MGS (2012) Nanoscale 4:1287. doi:10.1039/c2nr11536k

50. Shchukin DG, Zheludkevich M, Yasakau K, Lamaka S, Ferreira MGS, Möhwald H (2006) Adv Mater 18:1672. doi:10.1002/ adma.200502053

51. Gröger H, Gyger F, Leidinger P, Zurmühl C, Feldmann C (2009) Adv Mater 21:1586. doi:10.1002/adma.200802972

52. Lamaka SV, Zheludkevich ML, Yasakau KA, Montemor FM, Cecilio P, Ferreira MGS (2006) Electrochem Commun 8:421. doi:10.1016/j.elecom.2005.12.019

53. Balaskas AC, Kartsonakis IA, Tziveleka L-A, Kordas GC (2012) Prog Org Coat 74:418. doi:10.1016/j.porgcoat.2012.01.005

54. Snihirova D, Lamaka SV, Montemor MF (2012) Electrochim Acta 83:439. doi:10.1016/j.electacta.2012.07.102

55. Kouhi M, Mohebbi A, Mirzaei M (2012) Res Chem Intermed 39:2049. doi:10.1007/s11164-012-0736-1

56. Li GL, Zheng Z, Möhwald H, Shchukin DG (2013) ACS Nano 7:2470. doi:10.1021/nn305814q

57. Fix D, Andreeva DV, Lvov YM, Shchukin DG, Möhwald H (2009) Adv Funct Mater 19:1720. doi:10.1002/adfm.200800946

58. Tavandashti NP, Sanjabi S (2010) Prog Org Coat 69:384. doi:10. 1016/j.porgcoat.2010.07.012

59. Lvov YM, Shchukin DG, Möhwald H, Price RR (2008) J Nanosci Nanotechnol 2:814

60. Jiang X, Jiang Y-B, Liu N, Xu H, Rathod S, Shah P, Binker CF (2011) Journal of Nanomaterials 2011:1. doi:10.1155/2011/ 760237

61. Zheludkevich M, Serra R, Montemor M, Ferreira M (2005) Electrochem Commun 7:836. doi:10.1016/j.elecom.2005.04.039

62. Lamaka SV, Zheludkevich ML, Yasakau KA, Serra R, Poznyak SK, Ferreira MGS (2007) Prog Org Coat 58:127. doi:10.1016/j. porgcoat.2006.08.029

63. Khramov AN, Voevodin NN, Balbyshev VN, Donley MS (2004) Thin Solid Films 447-448:549. doi:10.1016/j.tsf.2003. 07.016 
64. Borisova D, Möhwald H, Shchukin DG (2012) Appl Mater \& Interfaces 4:2931. doi:10.1021/am300266t

65. Latnikova A, Grigoriev DO, Hartmann J, Möhwald H, Shchukin DG (2011) Soft Matter 7:369. doi:10.1039/c0sm00842g

66. Suryanarayana C, Rao KC, Kumar D (2008) Prog Org Coat 63:72. doi:10.1016/j.porgcoat.2008.04.008

67. Fickert J, Wohnhaas C, Turshatov A, Landfester K, Crespy D (2013) Macromolecules 46:573. doi:10.1021/ma302013s

68. Sauvant-Moynot V, Gonzalez S, Kittel J (2008) Prog Org Coat 63:307. doi:10.1016/j.porgcoat.2008.03.004

69. E. Matter, S. Kozhukharov, M. Machkova VК (2009). НАУЧНИ ТРУДОВЕ НА РУСЕНСКИЯ УНИВЕРСИТЕТ 48:19

70. Zheludkevich ML, Shchukin DG, Yasakau KA, Möhwald H, Ferreira MGS (2007) Chem Mater 19:402

71. Tatiya PD, Hedaoo RK, Mahulikar PP, Gite VV (2013) Ind Eng Chem Res 52:1562. doi:10.1021/ie301813a

72. Borisova D, Möhwald H, Möhwald H, Shchukin DG (2011) ACS Nano 5(3):1939

73. Moustafa EM, Dietz A, Hochsattel T (2013) Surf Coat Technol 216:93. doi:10.1016/j.surfcoat.2012.11.030

74. Javierre E, García SJ, Mol JMC, Vermolen FJ, Vuik C, van der Zwaag S (2012) Prog Org Coat 75:20. doi:10.1016/j.porgcoat. 2012.03.002

75. Samadzadeh M, Boura SH, Peikari M, Kasiriha SM, Ashrafi A (2010) Prog Org Coat 68:159. doi:10.1016/j.porgcoat.2010.01.006

76. Kumar A, Stephenson LD, Murray JN (2006) Prog Org Coat 55:244. doi:10.1016/j.porgcoat.2005.11.010

77. Latnikova A, Grigoriev D, Schenderlein M, Möhwald H, Shchukin D (2012) Soft Matter 8:10837. doi:10.1039/c2sm26100f

78. Rosero-Navarro NC, Paussa L, Andreatta F, Castro Y, Duran A, Aparicio M, Fedrizzi L (2010) Prog Org Coat 69:167. doi:10. 1016/j.porgcoat.2010.04.013

79. Rosero-Navarro NC, Pellice SA, Durán A, Aparicio M (2008) Corros Sci 50:1283. doi:10.1016/j.corsci.2008.01.031

80. Andreatta F, Paussa L, Aldighieri P, Fedrizzi L Electrochemical behaviour of $\mathrm{ZrO}_{2}$ sol-gel fi lms doped with corrosion inhibitors on AA2024 aluminium alloy. 262-278

81. Montemor MF, Trabelsi W, Lamaka SV, Yasakau KA, Zheludkevich ML, Bastos AC, Ferreira MGS (2008) Electrochim Acta 53:5913. doi:10.1016/j.electacta.2008.03.069

82. Montemor MF, Pinto R, Ferreira MGS (2009) Electrochim Acta 54:5179

83. Wu L-K, Liu L, Li J, Hu JM, Zhang JQ, Cao CN (2010) Surf Coat Technol 204:3920. doi:10.1016/j.surfcoat.2010.05.027

84. Bardon J, Bour J, Aubriet H, Ruch D, Verheyde B, Dams R, Paulussen S, Rego R, Vangeneugden D (2007) Plasma Processes Polym 4:S445. doi:10.1002/ppap.200731204

85. Paussa L, Rosero-Navarro NC, Andreatta F, Castro Y, Duran A, Aparicio M, Fedrizzi L (2010) Surf Interface Anal 42:299. doi:10.1002/sia.3198

86. Pepe A, Aparicio M, Ceré S, Durán A (2004) J Non-Cryst Solids 348:162. doi:10.1016/j.jnoncrysol.2004.08.141

87. Pepe A, Aparicio M, Durán A, Ceré S (2006) J Sol-Gel Sci Technol 39:131. doi:10.1007/s10971-006-9173-1

88. Andreatta F, Paussa L, Aldighieri P, Lanzutti A, Raps D, Fedrizzi L (2010) Prog Org Coat 69:133. doi:10.1016/j.porgcoat. 2010.04.012

89. Paussa L, Rosero Navarro NC, Bravin D, Andreatta F, Lanzutti A, Aparicio M, Duran A, Fedrizzi L (2012) Prog Org Coat 74:311. doi:10.1016/j.porgcoat.2011.08.017

90. Rosero-Navarro NC, Curioni M, Castro Y, Aparicio M, Thompson GE, Duran A (2011) Surf Coat Technol 206:257. doi:10.1016/j.surfcoat.2011.07.006

91. Rosero-Navarro NC, Pellice SA, Durán A, Ceré S, Aparicio M (2009) J Sol-Gel Sci Technol 52:31. doi:10.1007/s10971-0092010-6
92. Motte C, Poelman M, Roobroeck A, Fedel M, Deflorian F, Olivier MG (2012) Prog Org Coat 74:326. doi:10.1016/j. porgcoat.2011.12.001

93. Collazo A, Covelo A, Nóvoa XR, Pérez C (2012) Prog Org Coat 74:334. doi:10.1016/j.porgcoat.2011.10.001

94. Madani SM, Ehteshamzadeh M, Rafsanjani HH, Mansoori SS (2009) Mater Corros 61:318. doi:10.1002/maco.200905306

95. Hosseini SM, Jafari AH, Jamalizadeh E (2009) Electrochim Acta 54:7207. doi:10.1016/j.electacta.2009.07.002

96. Trabelsi W, Cecilio P, Ferreira MGS, Montemor MF (2005) Prog Org Coat 54:276. doi:10.1016/j.porgcoat.2005.07.006

97. Yasakau KA, Zheludkevich ML, Karavai OV, Ferreira MGS (2008) Prog Org Coat 63:352. doi:10.1016/j.porgcoat.2007.12. 002

98. Zaharescua M, Predoana LA, Barau A, Raps D, Gammel F, Rosero-Navarro NC, Castro Y, Duran A, Aparicio M (2009) Corros Sci 51:1998

99. Roussi E, Tsetsekou A, Tsiourvas D, Karantonis A (2011) Surf Coat Technol 205:3235. doi:10.1016/j.surfcoat.2010.11.037

100. Palomino LM, Suegama PH, Aoki IV, Montemor FM, De Melo HG (2009) Corros Sci 51:1238

101. Montemor MF, Ferreira MGS (2008) Prog Org Coat 63:330. doi:10.1016/j.porgcoat.2007.11.008

102. Li S, Fu J (2013) Corros Sci 68:101. doi:10.1016/j.corsci.2012. 10.040

103. Franquet A, Le Pen C, Terryn H, Vereecken J (2003) Electrochim Acta 48:1245. doi:10.1016/S0013-4686(02)00832-0

104. Zhu D, van Ooij WJ (2003) Corros Sci 45:2177. doi:10.1016/ S0010-938X(03)00061-1

105. Palanivel V, Huang Y, van Ooij WJ (2005) Prog Org Coat 53:153

106. Fedrizzi L, Fürbeth W, Montemor MF (2011) Self-healing properties of new surface treatments. Maney Publishing, Wakefield

107. Aramaki K (2003) Corros Sci 45:2361

108. Aramaki K (2003) Corros Sci 45:199. doi:10.1016/S0010$938 \mathrm{X}(02) 00086-0$

109. Aramaki K (2003) Corros Sci 45:1085

110. Hamdy AS, Doench I, Möhwald H (2011) Thin Solid Films 520:1668. doi:10.1016/j.tsf.2011.05.080

111. Hamdy AS, Doench I, Möhwald H (2012) Surf Coat Technol 206:3686. doi:10.1016/j.surfcoat.2012.03.025

112. Ramezanzadeh B, Attar MM, Farzam M (2010) Surf Coat Technol 205:874. doi:10.1016/j.surfcoat.2010.08.028

113. Yuan M, Lu J, Kong G, Che C (2011) Surf Coat Technol 205:4507. doi:10.1016/j.surfcoat.2011.03.088

114. Hamdy AS, Doench I, Möhwald H (2011) Electrochim Acta 56:2493. doi:10.1016/j.electacta.2010.11.103

115. Hamdy AS, Butt DP (2013) Electrochim Acta 97:296. doi:10. 1016/j.electacta.2013.02.108

116. Yabuki A, Kaneda R (2009) Mater Corros 60:444. doi:10.1002/ maco. 200805100

117. Koleva DA, Boshkov N, Bachvarov V, Zhann H, de Wit JHW, van Breugel K (2010) Surf Coat Technol 204:3760. doi:10.1016/ j.surfcoat.2010.04.043

118. Yabuki A, Sakai M (2011) Corros Sci 53:829. doi:10.1016/j. corsci.2010.11.021

119. Yang HJ, Pei YT, Rao JC, De Hosson JTM (2012) J Mater Chem 22:8304. doi:10.1039/c2jm16123k

120. Gao J, Suo J (2011) Surf Coat Technol 206:1342. doi:10.1016/j. surfcoat.2011.08.059

121. Neema S, Selvaraj M, Raguraman J, Ramu S (2013) J Appl Polym Sci 127:740. doi:10.1002/app.37791

122. Snihirova D, Liphardt L, Grundmeier G, Montemor F (2013) J Solid State Electrochem. doi:10.1007/s10008-013-2078-3 